\title{
Fasting heat production and energy cost of standing activity in veal calves
}

\author{
Etienne Labussière ${ }^{1,2}$, Serge Dubois ${ }^{1}$, Jaap van Milgen ${ }^{1}$, Gérard Bertrand ${ }^{2}$ and Jean Noblet ${ }^{1 *}$ \\ ${ }^{1}$ INRA, UMR 1079 Systèmes d'Elevage Nutrition Animale et Humaine, F-35590 Saint-Gilles, France \\ ${ }^{2}$ Institut de l'Elevage, Monvoisin, BP 85225, F-35652 Le Rheu Cedex, France \\ (Received 15 November 2007 - Revised 11 January 2008 - Accepted 17 March 2008 - First published online 29 April 2008)
}

Metabolic body size of veal calves is still calculated by using the 0.75 exponent and no data were available to determine energy cost of physical activity during the whole fattening period. Data from two trials focusing on protein and/or energy requirements were used to determine the coefficient of metabolic body size and the energy cost of standing activity in male Prim'Holstein calves. Total heat production was measured by indirect calorimetry in ninety-five calves weighing 60-265 kg and was divided using a modelling approach between components related to the BMR, physical activity and feed intake. The calculation of the energy cost of standing activity was based on quantifying the physical activity by using force sensors on which the metabolism cage was placed and on the interruption of an IR beam allowing the determination of standing or lying position of the calf. The best exponent relating zero activity fasting heat production $\left(\mathrm{FHP}_{0}\right)$ to metabolic body size was $0 \cdot 85$, which differed significantly from the traditionally used $0 \cdot 75$. Per additional kJ metabolizable energy (ME) intake, $\mathrm{FHP}_{0}$ increased by $0.28 \mathrm{~kJ}$; at a conventional daily $650 \mathrm{~kJ} / \mathrm{kg}$ body weight $(\mathrm{BW})^{0.85} \mathrm{ME}$ intake, daily $\mathrm{FHP}_{0}$ averaged $310 \mathrm{~kJ} / \mathrm{kg} \mathrm{BW}^{0.85}$. Calves stood up sixteen times per day; total duration of standing increased from $5 \cdot 1$ to $6 \cdot 4 \mathrm{~h}$ per day as animals became older. The hourly energy cost of standing activity was proportional to $\mathrm{BW}^{0.65}$ and was estimated as $12.4 \mathrm{~kJ} / \mathrm{kg} \mathrm{BW}^{0.65}$. These estimates allow for a better estimation of the maintenance energy requirements in veal calves.

Veal calves: Heat production: Metabolic body size: Fasting heat production: Physical activity

Knowledge on nutrient requirements of veal calves is mainly based on studies carried out during the $1960 \mathrm{~s}$ and $1970 \mathrm{~s}^{(1,2)}$ although there has recently been increased research interest in veal calf production ${ }^{(3-8)}$. Indeed, the conditions of fattening have greatly evolved since then in terms of breeds of the animals used as well as the body weight (BW) range of the fattening period. Metabolizable energy (ME) requirements have been determined according to a factorial method as the sum of the maintenance and production requirements. The maintenance ME requirement, which represents between 30 and $40 \%$ of the total energy requirement in veal calves, can be estimated from the measurement of the fasting heat production $(\mathrm{FHP})^{(9)}$ or from extrapolating regression equations to zero $\mathrm{ME}$ intake or zero energy retention. However, values for FHP often include a contribution of physical activity and depend on the length of fasting whereas the regression method is not very accurate for estimating maintenance requirement ${ }^{(10)}$ as it needs data in a wide range of ME intakes both above and below maintenance. Data on the latter are very scarce in the literature. The FHP, which is thought to be representative of the $\mathrm{BMR}^{(11)}$, corresponds to the minimum energy expenditure of resting, healthy, non-reproductive, fasting and adult animals that are in a thermoneutral environment during the inactive circadian phase ${ }^{(12)}$. BMR and, consequently, FHP are usually considered to be proportional to metabolic body size (i.e. body weight with an allometric exponent). The 0.75 exponent for the calculation of metabolic body size has been widely adopted for comparisons between species in mature animals ${ }^{(13)}$. However, several alternatives have been proposed in the last decades ${ }^{(14)}$ suggesting that the 0.75 exponent has to be re-evaluated ${ }^{(15)}$. The value of 0.65 appears to be more adequate for intra-specific comparisons in mature animals ${ }^{(16)}$, and studies in growing pigs $^{(10,17)}$ and chickens suggest that other values may be more adequate. To our knowledge, no studies have been carried out in growing veal calves that allows appropriate expression of the maintenance energy requirement relative to BW. In addition, the effect of standing activity on the maintenance energy requirement and on metabolic exponent has received little attention. This is all the more surprising as group-housing of veal calves has become mandatory in the European Union, which has resulted in an increase in energy expenditure for physical activity in relation to higher levels of physical activity ${ }^{(18)}$. In the few existing studies conducted in young animals ${ }^{(19)}$ $(<1$-month-old), the effect of standing activity on heat production in veal calves has been accounted as the difference in average heat production measured during periods of standing and lying, which is probably insufficient to get an accurate estimate of the energy cost of physical activity ${ }^{(20)}$. In fact, the percentage of standing during the few hours following the meal was higher than later in the day and the

Abbreviations: AHP, heat production due to activity; BW, body weight; $\mathrm{C}_{\mathrm{st}}$, energy cost of standing; $\mathrm{D}_{\mathrm{st}}$ and $\mathrm{D}_{\text {ly }}$, duration of standing and lying respectively; $\mathrm{CP}$, crude protein; $\mathrm{F}_{\mathrm{st}}$ and $\mathrm{F}_{\mathrm{ly}}$, forces sensed during periods of standing and lying respectively; FHP, fasting heat production; $\mathrm{FHP}_{0}$, FHP at zero activity level; ME, metabolizable energy.

* Corresponding author: Dr Jean Noblet, fax +332234850 80, email jean.noblet@rennes.inra.fr 
difference consequently included part of heat production due to the digestive and metabolic utilizations of the meal ${ }^{(21)}$.

The objectives of this study were to use data from two experiments on veal calves to determine the variation of $\mathrm{FHP}_{0}$ in relation to $\mathrm{BW}$ as well as quantifying the effect of physical activity on heat production.

\section{Materials and methods}

\section{Experimental design}

Two trials were carried out to determine the effect of protein content (trial 1) or energy intake (trial 2) on protein and lipid deposition and on heat production in veal calves. These data were obtained using the nitrogen and energy balance techniques at three growing (5-8 weeks, stage 1) and finishing (13-17 weeks, stage 2 and 21-26 weeks, stage 3) stages. In both trials, fattening of calves occurred at the Institut de l'Elevage experimental station in Le Rheu (France) whereas the balances were carried out at the INRA facilities in Saint-Gilles (France). The two sites were within $10 \mathrm{~km}$ of each other. In trial 1, four milk replacers with four levels of protein were used at each stage. Trial 2 was designed to study the effects of feed supply by using a single milk replacer offered at four feeding levels at each stage. Milk replacers used during the two finishing stages were the same. No solid feed was provided in either trial. The objective was to measure four calves at each stage on each dietary treatment, i.e. forty-eight measurements per trial.
Calves were purchased at $7-15 \mathrm{~d}$ actual age. Week 1 corresponds to the first week after arrival at the facilities.

As two large-size respiration chambers were available, two balances could be performed each week. Therefore, measurements for one stage were conducted over four successive weeks and two successive batches of calves were used in each trial, calves of the second batch being purchased four weeks later. Each measurement week consisted of a $6 \mathrm{~d}$ nitrogen and energy balance with two equal meals per day followed by a fasting day where the calves received only a morning meal. The measurements during the last day were designed to obtain an estimate of the $\mathrm{FHP}_{0}$ by way of a direct measurement using a modeling approach (see later) but consecutive to different feeding strategies. Main characteristics of calves and feeding strategies are summarized in Table 1.

The purpose of the present study is to analyse the heat production measurements during the fasting day in order to propose a method for evaluating $\mathrm{FHP}_{0}$ in veal calves. Data of both trials for all measurement days (excluding the fasting days) will also be used to evaluate the energy cost of physical activity.

\section{Experimental diets}

The diets used were formulated using skimmed milk, lactose and $50 \%$ fat-enriched skimmed milk; the fat of the latter was a mixture of $55 \%$ coconut oil, $25 \%$ lard and $20 \%$ tallow. Composition and most important characteristics of experimental diets are presented in Table 2. For trial 1, eight

Table 1. Age, body weight (BW) and milk DM intakes of calves

$\mathrm{RSE}^{*}$

Significance $†$

Trial 1

CP content (\% of reference)

Age (week)

1

2

Body weight $(\mathrm{kg})$

1

2

3

DM intake $(\mathrm{kg} / \mathrm{d})$

1

2

Trial 2

$\mathrm{FL}$ (\% of reference)

Age (week)

1

2

BW $(\mathrm{kg})$

1

2

3

DM intake $(\mathrm{kg} / \mathrm{d})$

1

2

3
76

73

135

212

1.30

$2 \cdot 14$

$2 \cdot 80$

79

73

150

242

1.08
1.97

2.69
88

100

5 to 8

13 to 16

21 to 24

75
140

140

216

1.31

2.10

$2 \cdot 78$

87

14 to 17

23 to 26

75
149
239

$1 \cdot 21$
$2 \cdot 15$
2.91

76
142
221

1.30
$2 \cdot 14$
$2 \cdot 74$

95
112

78
142
217

$1 \cdot 32$
$2 \cdot 12$
$2 \cdot 75$

103

12

S

$0 \cdot 13$

S

103

$\mathrm{CP}$, crude protein; FL, feeding level.

${ }^{*}$ Residual standard error of the model $Y=\mu+P+S+P \times S+\varepsilon$ for trial 1 where $\mu$ is the average intercept, $P$ is the effect of CP content of the diet, $S$ is the effect of stage of fattening and $P \times S$ is the interaction between $C P$ content of the diet and stage, and $Y=\mu+F+S+F \times S+\varepsilon$ for trial 2 , where $\mu$ is the average intercept, $F$ is the effect of feeding level, $S$ is the effect of stage of fattening and $F \times S$ is the interaction between feeding level and stage.

$\dagger \mathrm{F}$, effect of feeding level $(P<0.05)$; $\mathrm{S}$, effect of stage of fattening $(P<0.05)$. 
Table 2. Composition and characteristics of milk replacers in experimental diets given to growing $(G)$ and finishing $(F)$ veal calves*

\begin{tabular}{|c|c|c|c|c|c|c|c|c|c|c|}
\hline \multirow{3}{*}{$\begin{array}{l}\text { Trial... } \\
\text { Stage... } \\
\text { Milk replacer... }\end{array}$} & \multicolumn{8}{|c|}{1} & \multicolumn{2}{|c|}{2} \\
\hline & \multicolumn{4}{|c|}{$G$} & \multicolumn{4}{|c|}{$\mathrm{F} 1-\mathrm{F} 2$} & \multirow{2}{*}{$\begin{array}{c}\mathrm{G} \\
\mathrm{G}_{2}\end{array}$} & \multirow{2}{*}{$\frac{\mathrm{F} 1-\mathrm{F} 2}{\mathrm{~F}_{2}}$} \\
\hline & $\mathrm{G}_{76}$ & $\mathrm{G}_{88}$ & $\mathrm{G}_{100}$ & $\mathrm{G}_{112}$ & $F_{76}$ & $F_{88}$ & $\mathrm{~F}_{100}$ & $\mathrm{~F}_{112}$ & & \\
\hline \multicolumn{11}{|l|}{ Ingredient $(\mathrm{g} / \mathrm{kg})$} \\
\hline SMP & 214.5 & 287.0 & $359 \cdot 1$ & 426.6 & 181.5 & 249.3 & $319 \cdot 0$ & $385 \cdot 0$ & 473.6 & $396 \cdot 2$ \\
\hline $50 \%$-fat enriched SMP & 369.9 & $352 \cdot 1$ & 333.9 & $315 \cdot 3$ & $375 \cdot 1$ & $356 \cdot 4$ & 338.4 & $323 \cdot 7$ & $312 \cdot 0$ & 324.4 \\
\hline Lactose & 339.5 & 290.9 & $242 \cdot 9$ & $201 \cdot 0$ & 364.0 & 322.0 & $277 \cdot 3$ & $230 \cdot 0$ & 155.6 & $217 \cdot 3$ \\
\hline Wheat starch & $30 \cdot 0$ & $30 \cdot 0$ & $30 \cdot 0$ & $30 \cdot 0$ & $30 \cdot 0$ & $30 \cdot 0$ & $30 \cdot 0$ & $30 \cdot 0$ & $30 \cdot 0$ & $30 \cdot 0$ \\
\hline Others $\dagger$ & $46 \cdot 0$ & $40 \cdot 0$ & 34.0 & $27 \cdot 0$ & $49 \cdot 3$ & $42 \cdot 3$ & $35 \cdot 3$ & 31.3 & 28.9 & $32 \cdot 2$ \\
\hline DM $(\mathrm{g} / \mathrm{kg})$ & 954 & 954 & 953 & 959 & 962 & 960 & 962 & 960 & 930 & 953 \\
\hline \multicolumn{11}{|l|}{ Nutrients $\ddagger$ (g/kg DM) } \\
\hline Crude protein & 163 & 189 & 213 & 235 & 150 & 174 & 197 & 221 & 246 & 219 \\
\hline Lactose & 592 & 573 & 557 & 541 & 592 & 584 & 562 & 546 & 461 & 496 \\
\hline Fat & 197 & 185 & 174 & 164 & 187 & 177 & 168 & 161 & 164 & 165 \\
\hline Gross energy $\ddagger$ (MJ/kg DM) & 20.99 & 20.95 & 20.99 & 20.93 & $20 \cdot 74$ & $20 \cdot 71$ & $20 \cdot 79$ & 20.79 & 20.93 & 20.98 \\
\hline ME† (MJ/kg DM) & 19.02 & 19.53 & 19.64 & 19.55 & $18 \cdot 26$ & 18.05 & 18.57 & 18.80 & 19.38 & $18 \cdot 83$ \\
\hline
\end{tabular}

SMP, skimmed milk powder; ME, metabolizable energy.

${ }^{*}$ For details of diet formulations and application see Materials and methods.

$\dagger$ This fraction included amino acids, minerals and vitamins.

$\ddagger$ As measured.

diets differing in crude protein (CP) levels were formulated to obtain two groups (one for the growing stage and one for the two finishing stages) of four isoenergetic diets differing in their CP levels. The CP levels were considered as a percentage of a reference CP level which was assumed to be $20 \%$ for growing diets and $19 \%$ for finishing diets. For each type of diet, the four CP levels were then calculated as 76, 88, 100 and $112 \%$ of these reference levels and referred to as $\mathrm{G}_{76}, \mathrm{G}_{88}, \mathrm{G}_{100}$ and $\mathrm{G}_{112}$ for the growing diets and $\mathrm{F}_{76}, \mathrm{~F}_{88}, \mathrm{~F}_{100}$ and $\mathrm{F}_{112}$ for the finishing diets. They were achieved by substituting $\mathrm{CP}$ by a mixture of lactose and fat at the same energy concentration. During the second trial, one milk replacer was formulated for the growing stage $\left(G_{2}\right)$ and another one $\left(F_{2}\right)$ was formulated for finishing stages using the same ingredients and it was offered to the calves at four levels that were calculated as 79, 87, 95 and $103 \%$ of a reference feeding level commonly used at the Institut de l'Elevage experimental station.

Liquid milk was reconstituted just before distribution by dissolving the powder in hot water $\left(65^{\circ} \mathrm{C}\right)$ at a concentration that increased with $\mathrm{BW}$ from 130 to $175 \mathrm{~g}$ milk DM/kg milk replacer. The milk replacer was offered to the calves at a temperature ranging from 45 to $50^{\circ} \mathrm{C}$ at two equal meals at 08.45 hours and 18.00 hours. Average quantities of DM are given in Table 1. To avoid long-term disturbances in performance of the calves due to insufficient protein or energy supply, they were fed the reference diet (during trial 1) or at the reference feeding level (trial 2) out of the adaptation (two weeks) and measurement (one week) periods.

\section{Animals, housing and management}

Twenty-eight and fifty Prim'Holstein male calves were available for trials 1 and 2, respectively. Some calves were measured twice at two different stages (mainly for the first trial) but measurements with repeatedly used calves were considered independent due to the large delay between two successive measurements ( 8 weeks); during this period, calves moved back to the Institut de l'Elevage facilities where they were fed a reference milk replacer (trial 1) or at a reference feeding level (trial 2). In total, sixty-one calves were measured during ninety-six 1-week periods. Each week, two calves were moved from the pen to individual cages with wooden slatted floors at the Institut de l'Elevage experimental station (Le Rheu, France). After 1 week, calves were transferred to the INRA facilities (Saint-Gilles, France; $10 \mathrm{~km}$ from the Institut de l'Elevage) for a further 1-week adaptation period in similar metabolism crates. At INRA, the two cages were placed in the same room but separated by a curtain in order to avoid visual contact between the calves. The calves were bucket-fed automatically without direct human contact. The automated feeding procedure consisted of a 4 min distribution of the milk replacer (previously stored and constantly stirred in a plastic container) through the bottom of the bucket. After a 10 min time span, refusals were pumped through the bottom of the bucket and 1 litre of hot water (at approximately $50^{\circ} \mathrm{C}$ ) was poured in the bucket and also pumped to the plastic can in order to rinse the distribution system (diluted refusals). Two days before their entrance to the respiration chamber, calves were harnessed with plastic bags to allow total faeces collection.

During the measurement week, the calf in its metabolism cage was placed in a $12 \mathrm{~m}^{3}$ open-circuit respiration chamber $^{(22)}$. The cage was mounted on force sensors (9104A, Kistler, Switzerland; Saint-Gilles, France) which produced an electrical signal proportional to the physical activity of the calf ${ }^{(23)}$. The position of the animal (standing or lying) was measured using an IR beam placed across the cage at the bottom of the standing calf's hip. The temperature and relative humidity of the air in the chamber were maintained constant at $18^{\circ} \mathrm{C}$ and $70 \%$, respectively. A $12 \mathrm{~h}$ lighting time span (07.30 to 19.30 hours) was used. Both chambers were equipped with microphones and speakers to allow the calves to hear each other. As during the adaptation period, calves were fed automatically while in the respiration chambers. Each morning before the meal, the gas concentration measurements were stopped for about $30 \mathrm{~min}$ and 
faeces bags were collected, some care was provided to the animals and gas analysers were calibrated. Mean BW of calves during the measurement week are given in Table 1 .

\section{Measurements}

The quantity of milk replacer offered to each calf when housed in the respiration chamber was weighed and milk replacer was sampled over the balance period. Diluted refusals were weighed for each calf after each meal and a $20 \mathrm{ml}$ sample was frozen. Faeces were collected, weighed daily and then stored at $-20^{\circ} \mathrm{C}$ and pooled per calf over the $6 \mathrm{~d}$ balance period for further analyses. Urine was collected in buckets containing $120 \mathrm{ml}$ (period 1) or $240 \mathrm{ml}$ (periods 2 and 3) $\mathrm{H}_{2} \mathrm{SO}_{4}(1.8 \mathrm{~mol} / \mathrm{l})$ to prevent volatilization of ammonia. The urine produced was weighed daily and an aliquot was taken; aliquots were pooled per calf over the balance period and stored at $+4^{\circ} \mathrm{C}$ for subsequent analyses.

Gas concentrations $\left(\mathrm{CO}_{2}, \mathrm{O}_{2}\right)$ of outgoing air and ventilation rate were recorded continuously according to van Milgen et al. ${ }^{(24)}$ The $\mathrm{O}_{2}$ was measured with a paramagnetic differential analyser (Oxymat 6, Siemens AG, Munich, Germany; Saint-Gilles, France), whereas $\mathrm{CO}_{2}$ was measured with an IR analyser (Ultramat 6, Siemens AG, Munich, Germany or Unor 600, Maihak AG, Hamburg, Germany; Saint-Gilles, France). The gas extraction rate was measured with a mass gas meter (Teledyne Brown Engineering, Hampton, Virginia, USA; Saint-Gilles, France). Gas concentrations, the signals of the force sensors, the weight of the distribution recipient and physical characteristics of gas in the chamber were measured sixty times per second, averaged over $10 \mathrm{~s}$ intervals, and recorded for further calculations.

\section{Chemical analyses}

Pooled samples of faeces and urine were analysed for DM, crude protein and gross energy contents according to standard procedures $^{(25)}$. The same analyses were performed on samples of milk replacers. The DM content was determined on diluted refusals. The composition of DM refusals was assumed to be identical to that of the offered DM.

\section{Calculations}

The DM intake was calculated for each meal as the difference between the offered DM and DM in diluted refusals. Mean ME ingested by each calf was calculated as the difference between daily ingested gross energy and daily energy losses in faeces and urine. When expressed relative to DM intake, the ME content of the milk replacer was calculated for each balance period.

Calves were weighed before the morning meal at the beginning and at the end of each measurement week. It was important to get a BW measurement on the morning of the fasting day for evaluating mean $\mathrm{BW}$ or $\mathrm{BW}$ gain over the fed period (i.e. the first $6 \mathrm{~d}$ in the respiration chamber). However, the BW measurement procedure seemed to cause stress to the animal which may have consequences on measurements during the fasting day. Therefore, these measurements were carried out only in trial 1 on all calves at the growing stage and calves of the first batch at the finishing stages. These measurements were used in a linear regression procedure to estimate the weight loss during the fasting day. For all other data, the BW measurement after fasting, combined with the estimated BW loss during fasting was used to calculate the morning $\mathrm{BW}$ prior to fasting $\left(\mathrm{BW}_{\mathrm{f}}\right)$ for all other calves. Mean growth rate and mean body weight $\left(\mathrm{BW}_{\mathrm{m}}\right)$ during balance measurement were then calculated using $\mathrm{BW}_{\mathrm{f}}$ and the entrance $\mathrm{BW}$. Assuming a constant growth rate over the balance measurement, morning BW was estimated for each day.

Simultaneous measurements of $\mathrm{O}_{2}$ consumption and $\mathrm{CO}_{2}$ production, signals of force sensors, data concerning meals (time of distribution and ingested quantity) and physical characteristics of the gas in the chamber were used to calculate the components of heat production ${ }^{(24)}$ (Fig. 1). The variations in $\mathrm{O}_{2}$ and $\mathrm{CO}_{2}$ concentrations in the chamber were related to $\mathrm{O}_{2}$ consumption and $\mathrm{CO}_{2}$ production by the calf. These gas exchanges were partitioned between $\mathrm{O}_{2}$ consumption and $\mathrm{CO}_{2}$ production during the resting state, physical activity and the thermic effect of feeding. Heat production due to activity, feed intake and resting metabolic rate and their associated RQ were then calculated from respective volumes of $\mathrm{O}_{2}$ consumption and $\mathrm{CO}_{2}$ production by the formula of Brouwer ${ }^{(26)}$ excluding urinary nitrogen losses. During the fasting day this modelling procedure was carried out on only the last $12 \mathrm{~h}$ using a simplified model that only included $\mathrm{O}_{2}$ consumption and $\mathrm{CO}_{2}$ production due to physical activity and the adaptation of the resting metabolism in the fed situation to a fasting situation. The latter was used to calculate FHP at zero activity level $\left(\mathrm{FHP}_{0}\right)$, which corresponded to the asymptotic value of metabolic rate at zero activity.

The energy cost of standing activity $\left(\mathrm{C}_{\mathrm{st}}, \mathrm{kJ} / \mathrm{h}\right.$ of standing) was estimated during the balance days in the chamber, excluding the first day considered as an adaptation day. Data from the IR beams were used to determine number of standing and lying periods and their durations $\left(D_{s t}\right.$ and $D_{l y}$, expressed in $\mathrm{h}$ ). The signals from force sensors were cumulated over periods of standing $\left(\mathrm{F}_{\mathrm{st}}, \mathrm{mV}\right)$ and lying $\left(\mathrm{F}_{\mathrm{ly}}, \mathrm{mV}\right)$ and $\mathrm{F}_{\mathrm{st}}$ was corrected from a daily baseline equal to $F_{l y} \times D_{s t} / D_{l y}$ which accounted for noise in the electrical signals from the force sensors that was mainly due to movements of the cage in relation to ventilation and for basal movements of the calves during lying. Finally, $\mathrm{C}_{\mathrm{st}}$, expressed per hour of standing position was then calculated from daily heat production due to activity (AHP) according to the formula

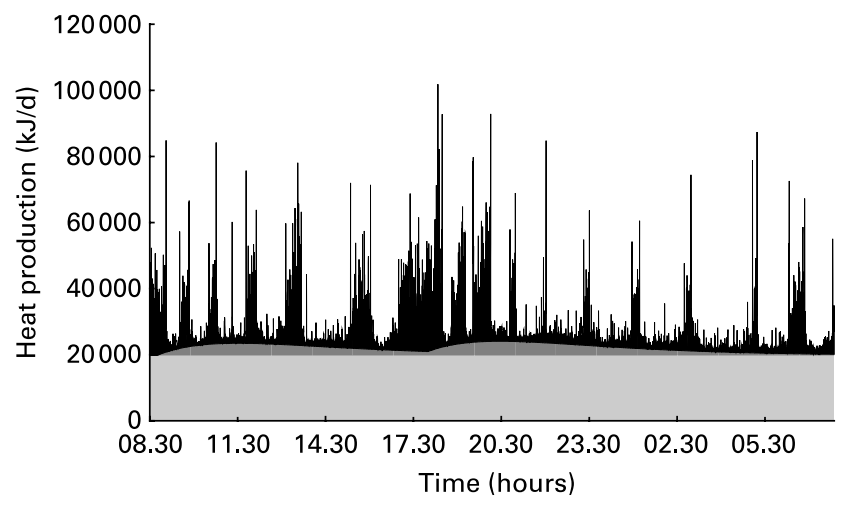

Fig. 1. Example of partition of heat production between components due to physical activity ( $\square$ ), feeding $(\square)$ and resting ( $\square$ ) from trial 1, for calf no. 15 in respiration chamber 1 on 5 June 2006. 
AHP $\times\left(F_{s t} / D_{\text {st }}-F_{\text {ly }} / D_{\text {ly }}\right) /\left(F_{\text {st }}+F_{\text {ly }}\right)$. These criteria were calculated for each available day of balance measurements, averaged over each balance period and mean values for each calf $(n 95)$ were used for subsequent statistical analyses.

\section{Statistics}

One observation was removed from the analysis in trial 2 due to failure to fit the heat production partition model of the fasting day to the data. All analyses were consequently carried out on ninety-five observations.

The effects of $\mathrm{CP}$ content of the diet $\left(\mathrm{P}_{i}\right)$, stage of fattening $\left(\mathrm{S}_{j}\right)$ and their interaction $\left(\mathrm{P}_{i} \times \mathrm{S}_{j}\right)$ in trial 1 and of feeding level $\left(\mathrm{F}_{i}\right)$, stage of fattening $\left(\mathrm{S}_{j}\right)$ and their interaction $\left(\mathrm{F}_{i} \times \mathrm{S}_{j}\right)$ in trial 2 on $\mathrm{BW}, \mathrm{DM}$ intake, ME intake, $\mathrm{FHP}_{0}$ and associated $\mathrm{RQ}$, daily number of bouts of standing, duration of standing, heat production due to standing expressed per hour of standing duration or related to daily ME intake and its associated RQ were tested using the GLM procedure of $\mathrm{SAS}^{(25)}$ according the following models (where $\mathrm{Y}$ is the dependent variable, $\mu$ is the average intercept and $\varepsilon$ is an error term):

$$
\begin{array}{ll}
Y=\mu+P+S+P \times S+\varepsilon & \text { for trial } 1 ; \\
Y=\mu+F+S+F \times S+\varepsilon & \text { for trial } 2 .
\end{array}
$$

As there was no effect of dietary $\mathrm{CP}$ content or interaction between dietary $\mathrm{CP}$ content and stage of fattening on these parameters in trial 1, only average results per stage are presented. Data of the fasting days from both trials were then pooled and $\mathrm{FHP}_{0}$ was considered as a function of the body weight of the morning of the fasting day $\left(\mathrm{BW}_{\mathrm{f}}\right)$. It was also assumed that, as in other species, the relation between $\mathrm{FHP}_{0}$ and $\mathrm{BW}_{\mathrm{f}}$ might be affected by the previous feeding level ${ }^{(26)}$ expressed as the mean of ME intake per $\mathrm{kg}$ metabolic body size $\left(\mathrm{BW}_{\mathrm{m}}^{\mathrm{c}_{i}}\right)$ during the $6 \mathrm{~d}$ prior to fasting. The following model was then considered in a first approach (for trial $i$ ) (where $\mathrm{a}_{i}, \mathrm{~b}_{i}$ and $\mathrm{c}_{i}$ are parameters to be estimated by the model $\mathrm{c}_{i}$ is the allometric exponent):

$$
\mathrm{FHP}_{0}=\left(\mathrm{a}_{i}+\mathrm{b}_{i} \times \mathrm{ME} / \mathrm{BW}_{\mathrm{m}}^{\mathrm{c}_{i}}\right) \times \mathrm{BW}_{\mathrm{f}}^{\mathrm{c}_{i}} .
$$

Preliminary analysis suggested that $\mathrm{FHP}_{0}$ variability increased with the level of $\mathrm{FHP}_{0}$. To account for this heteroscedasticity of the error, a logarithmic transformation of the model M1 and dependent variable $\mathrm{FHP}_{0}$ was performed:

$$
\log \left(\mathrm{FHP}_{0}\right)=\log \left(\left(\mathrm{a}_{i}+\mathrm{b}_{i} \times \mathrm{ME} / \mathrm{BW}_{\mathrm{m}}^{\mathrm{c}_{i}}\right) \times \mathrm{BW}_{\mathrm{f}}^{\mathrm{c}_{i}}\right) .
$$

Parameters of this model were estimated using the NLIN procedure of SAS ${ }^{(27)}$ with the Levenberg-Marquardt iteration algorithm. Hypotheses that $\mathrm{c}_{i}$ is equal for both trials or fixed at $0.75,0.80,0.85$ or 0.90 were tested according to the extrasum-of-squares test ${ }^{(28)}$.

For each model, the ninety-five residuals were ranked according to the ascending value of the predicted value associated with them and they were then partitioned into three groups of thirty two for the extremes and thirty-one residuals for the middle one and a Student's $t$ test was performed to test the equality of variances of the extreme groups using the TTEST procedure of $\mathrm{SAS}^{(27)}$.

Furthermore, $\mathrm{C}_{\mathrm{st}}$ was related to $\mathrm{BW}$ according to the general allometric model M3 and parameters were estimated using the NLIN procedure of SAS ${ }^{(18)}$ with the Levenberg-Marquardt iteration algorithm (for trial $i$ ):

$$
\mathrm{C}_{\mathrm{st}}=\mathrm{d}_{i} \times \mathrm{BW}^{\mathrm{e}},
$$

where $\mathrm{d}_{i}$ and e are parameters to be estimated by the model. Equality of parameters for the both trials $i$ was tested according to the extra-sum-of-squares test ${ }^{(28)}$.

\section{Results}

Determination of the coefficient of metabolic body size

The errors distribution of $\mathrm{FHP}_{0}$ presented in Fig. 2 illustrates the effect of the logarithmic transformation of the model: residuals are more homogeneous in Fig. 2 (B) (model M2, log-transformed) than in Fig. 2 (A) (model M1), in accordance with the statistics of the Student's $t$ test for the equality of variances $(0 \cdot 10 v .<0 \cdot 01)$. Model M2 was therefore considered for the subsequent analyses.

Results of the nonlinear regressions performed on $\log \left(\mathrm{FHP}_{0}\right)$ and associated tests are presented in Table 3. When considering different parameters in model M2 for

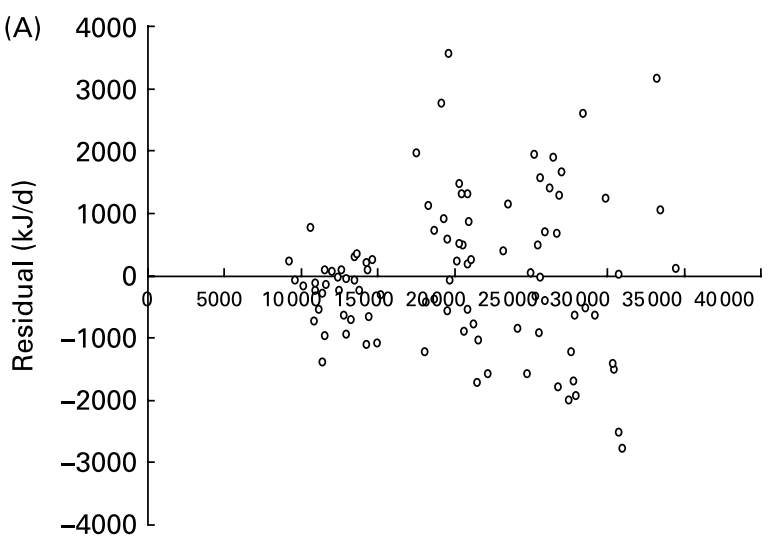

Predicted value $(\mathrm{kJ} / \mathrm{d})$

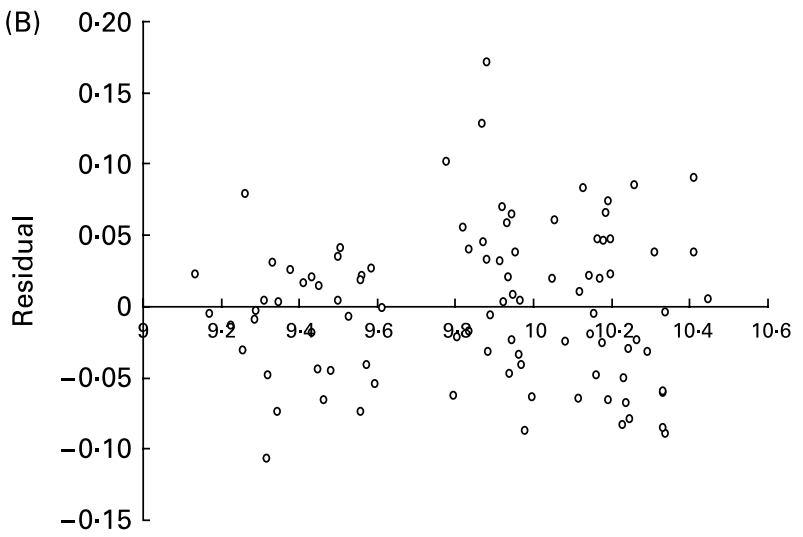

Predicted value

Fig. 2. Error distributions of the model $F H P_{0}=\left(a_{i}+b_{i} \times M E / B W_{m}^{c_{i}}\right) \times B W_{f}^{c_{i}}$ (A) or the model $\log \left(\mathrm{FHP}_{0}\right)=\log \left(\left(\mathrm{a}_{i}+\mathrm{b}_{i} \times \mathrm{ME} / \mathrm{BW}_{\mathrm{m}}^{\mathrm{c}_{i}}\right) \times \mathrm{BW}_{\mathrm{f}}^{\mathrm{c}_{i}}\right)(\mathrm{B})$, in trial $i$ (1 or 2) where $\mathrm{BW}_{\mathrm{m}}$ and $\mathrm{BW}_{\mathrm{f}}$ represent respectively mean BW during the $6 \mathrm{~d}$ prior to fasting and BW on the morning of the day of fasting, and ME is the mean metabolizable energy intake during the $6 \mathrm{~d}$ prior to the fast. Probability of significance of the difference between variances of the lowest and the highest groups was $P<0.01$ in $(A)$ and $P=0.10$ in (B). 
Table 3. Prediction of zero activity fasting heat production $\left(\mathrm{FHP}_{0}\right)$ in veal calves (see Fig. 2 for the errors distribution)*

\begin{tabular}{|c|c|c|c|c|c|c|c|c|c|c|c|}
\hline & \multirow[b]{2}{*}{ Trial $(i)$} & \multirow[b]{2}{*}{$P \dagger$} & \multicolumn{2}{|l|}{$a_{i}$} & \multicolumn{2}{|l|}{$\mathrm{b}_{i}$} & \multicolumn{2}{|c|}{$\mathrm{c}_{i}$} & \multicolumn{3}{|c|}{ Residuals } \\
\hline & & & Estimate & ASE & Estimate & ASE & Estimate & ASE & SE & Slopeł & $P$ \\
\hline \multirow{2}{*}{ Model M2 } & 1 & & 177 & 123 & 0.29 & 0.08 & 0.78 & 0.07 & 0.05 & 0.00 & 0.90 \\
\hline & 2 & & 145 & 37 & 0.23 & 0.04 & 0.86 & 0.03 & & & \\
\hline \multicolumn{12}{|l|}{ Reduced models } \\
\hline \multirow[t]{2}{*}{ equal $c$ for all $i$} & 1 & 0.38 & 90 & 32 & 0.34 & 0.04 & 0.86 & 0.03 & 0.05 & 0.00 & 0.98 \\
\hline & 2 & & 153 & 37 & 0.22 & 0.04 & & & & & \\
\hline \multirow[t]{2}{*}{$c$ fixed at 0.75} & 1 & $<0.01$ & 234 & 59 & 0.26 & 0.06 & 0.75 & - & 0.06 & 0.05 & $<0.01$ \\
\hline & 2 & & 246 & 38 & 0.24 & 0.04 & & & & & \\
\hline \multirow[t]{2}{*}{ c fixed at 0.80} & 1 & $0 \cdot 11$ & 149 & 35 & 0.30 & 0.05 & 0.80 & - & 0.05 & 0.03 & 0.11 \\
\hline & 2 & & 209 & 27 & 0.22 & 0.04 & & & & & \\
\hline \multirow[t]{2}{*}{ c fixed at 0.85} & 1 & 0.65 & 95 & 21 & 0.34 & 0.04 & 0.85 & - & 0.05 & 0.00 & 0.84 \\
\hline & 2 & & 159 & 20 & 0.22 & 0.03 & & & & & \\
\hline \multirow[t]{2}{*}{ c fixed at 0.90} & 1 & 0.31 & 62 & 14 & 0.37 & 0.03 & 0.90 & - & 0.05 & -0.01 & 0.37 \\
\hline & 2 & & 113 & 14 & 0.25 & 0.03 & & & & & \\
\hline$c$ fixed at 0.85 and equal $a$ and $b$ & & 0.07 & 130 & 15 & 0.28 & 0.03 & 0.85 & - & 0.06 & -0.01 & 0.60 \\
\hline
\end{tabular}

ASE, asymptotic SE.

${ }^{\star}$ Results obtained from the model $\log \left(\mathrm{FHP}_{0}\right)=\log \left(\left(\mathrm{a}_{i}+\mathrm{b}_{i} \times \mathrm{ME} / \mathrm{BW}_{\mathrm{m}}^{\mathrm{c}_{i}}\right) \times \mathrm{BW}_{\mathrm{f}}^{\mathrm{c}_{i}}\right)(\mathrm{M} 2)$ in trial $i(1$ or 2$)$, where $\mathrm{BW}_{\mathrm{m}}$ and $\mathrm{BW}_{\mathrm{f}}$ represent respectively mean $\mathrm{BW}$ during the $6 \mathrm{~d}$ prior to fasting and $\mathrm{BW}$ on the morning of the day of fasting and ME is the mean metabolizable energy intake during the $6 \mathrm{~d}$ prior to the fast.

†Probability that the residual sum of squares of the reduced model is equal to that of the full (M2). Hypothesis for which $P>0.05$ is indicative that the model is adequate for describing the data.

$\ddagger$ Slope of the regression between residuals of the model and predicted zero activity FHP (see Fig. 2) and the probability that it does not differ from 0 .

both trials, exponents for body weight were numerically different between trials: 0.78 for the trial 1 and 0.86 for trial 2. As asymptotic standard errors (ASE) are large and typically underestimated (0.07 for trial 1 and 0.03 for trial 2), CI of both trials could be partially confounded. Indeed, a single exponent of 0.86 (ASE 0.03) for both trials was sufficient to fit the data (for the extra-sum-of-squares test $P=0 \cdot 38$ ). This single coefficient differed from $0.75(P<0.01)$ but not from $0.80 \quad(P=0.11), 0.85 \quad(P=0.65)$ or $0.90 \quad(P=0.31)$. When considering the error distribution of each hypothesis, the 0.85 exponent was the most adequate for fitting the data (Table 3); the estimated slope (in the regression between residuals and fitted values of the model) calculated with the 0.85 exponent was closer to 0 than those calculated with other values of $c_{i}$ in model M2 (Table 3). Nevertheless, the slopes calculated when applying the different hypotheses did not differ significantly from 0 , except the one calculated when applying a 0.75 exponent $(P<0 \cdot 01)$.

\section{Variations of zero activity fasting heat production} with feeding level

Values of ME intakes during the $6 \mathrm{~d}$ prior to fasting, specified in Table 4, were in accordance with the experimental design: the ME intake in trial 1 was close to those realized in feeding levels 2 or 3 in trial 2 . When expressed per $\mathrm{kg} \mathrm{BW}^{085}$, values of $\mathrm{FHP}_{0}$ were close between both trials at similar ME intakes (Table 4). Nevertheless, in trial $2, \mathrm{FHP}_{0}$ increased with feeding level, irrespective of stage of growth. An increase of approximately $29 \%$ in ME intake between extreme feeding levels caused an increase in $\mathrm{FHP}_{0}$ of 14,10 or $12 \%$ at stages 1,2 or 3 , respectively. The value of $\mathrm{FHP}_{0}$ also decreased both in trials 1 and 2 as animals got older; in trial 2, the value of $\mathrm{FHP}_{0}$ for the third stage was the lowest $(P<0.01)$ and values for stages 1 and 2 did not differ at each feeding level. However, these stage effects are mainly due to differences in ME intake and there was no more effect of stage when considering ME intake as a covariate in the statistical model. This effect of ME intake on $\mathrm{FHP}_{0}$ is also illustrated in model M2 where the effect of ME intake on $\mathrm{FHP}_{0}$ is highly significant (Table 3). Fixing the exponent for the calculation of metabolic body size at 0.85 and assuming an equivalent effect of $\mathrm{ME}$ intake on $\mathrm{FHP}_{0}$ for both trials, the following equation $(P=0 \cdot 07$; extra-sum-of-squares test; Table 3) was obtained:

$$
\begin{aligned}
\mathrm{FHP}_{0} & =(130(\mathrm{ASE}=15)+0 \cdot 28(\mathrm{ASE} \\
& \left.=0 \cdot 03) \times \mathrm{ME} / \mathrm{BW}_{\mathrm{m}}^{0.85}\right) \times \mathrm{BW}_{\mathrm{f}}^{0.85},
\end{aligned}
$$

where $\mathrm{BW}_{\mathrm{m}}$ and $\mathrm{BW}_{\mathrm{f}}$ represent mean $\mathrm{BW}$ during the week prior to fasting and $\mathrm{BW}$ on morning of the fasting day, respectively. It can then be calculated that at $650 \mathrm{~kJ} / \mathrm{kg}$ $\mathrm{BW}^{085} \mathrm{ME}$ intake, $\mathrm{FHP}_{0}$ equals $310 \mathrm{~kJ} / \mathrm{kg} \mathrm{BW}^{085}$. RQ associated with $\mathrm{FHP}_{0}$ was not affected by stage or feeding level and it was comparable $(0 \cdot 77)$ for both trials.

\section{Estimation of the energy cost of physical activity}

On average, calves stood up sixteen times per day but with important variations between animals. Some calves stood up only twice daily whereas others stood up thirty-four times. Moreover, calves stood up fewer times in trial 1 than in trial 2, mainly as animals became older: in trial 1, the number of standing bouts decreased as animals became older $(P<0 \cdot 01$, Table 5) whereas it remained constant in trial 2. Total daily standing duration increased also as animals got older in both trials with similar average values at each stage for each trial (from 5.2 to $6.5 \mathrm{~h} / \mathrm{d}$ for trial 1 and from 5.0 to $6.3 \mathrm{~h} / \mathrm{d}$ for trial 2). If expressed as a percentage of ME intake, heat production due to standing tended to increase from 4.2 to $4.9 \%(P=0.12)$ as animals became older in trial 1 and increased $(P<0.01)$ from 3.8 (mean for stages 1 and 2$)$ to $4.6 \%$ (stage 3 ) in trial 2. Finally, energy cost of $1 \mathrm{~h}$ standing increased from 213 to $381 \mathrm{~kJ} / \mathrm{h}$ as animals became older 
Table 4. Zero activity fasting heat production $\left(\mathrm{FHP}_{0}\right)$ in veal calves

\begin{tabular}{|c|c|c|c|c|c|c|c|c|c|}
\hline \multirow[b]{3}{*}{ Stage } & \multicolumn{3}{|c|}{ Trial 1} & \multicolumn{6}{|c|}{ Trial 2} \\
\hline & \multirow[b]{2}{*}{ Mean } & \multirow[b]{2}{*}{ RSE $^{*}$} & \multirow[b]{2}{*}{ Significance $†$} & \multicolumn{4}{|c|}{ Feeding level } & \multirow[b]{2}{*}{ RSE $^{*}$} & \multirow[b]{2}{*}{ Significance $†$} \\
\hline & & & & 1 & 2 & 3 & 4 & & \\
\hline \multicolumn{10}{|c|}{ ME intake‡ (kJ/kg BW ${ }^{0.85}$ per d) } \\
\hline 1 & $642^{\mathrm{a}}$ & & & 541 & 592 & 641 & 694 & & \\
\hline 2 & $592^{b}$ & 24 & $\mathrm{~s}$ & 522 & 568 & 607 & 673 & 30 & $F, S$ \\
\hline 3 & $518^{\mathrm{C}}$ & & & 492 & 518 & 564 & 605 & & \\
\hline \multicolumn{10}{|c|}{$\mathrm{FHP}_{0}\left(\mathrm{~kJ} / \mathrm{kg} \mathrm{BW} \mathrm{BW}^{0.85}\right.$ per d) } \\
\hline 1 & $321^{a}$ & & & 277 & 285 & 312 & 315 & & \\
\hline 2 & $306^{\mathrm{b}}$ & 18 & $\mathrm{~s}$ & 289 & 295 & 300 & 318 & 16 & $F, S$ \\
\hline 3 & $272^{c}$ & & & $267 \S$ & 268 & 286 & 300 & & \\
\hline \multicolumn{10}{|c|}{$\mathrm{RQ}$ associated with $\mathrm{FHP}_{0}$} \\
\hline 1 & 0.78 & & & 0.76 & 0.74 & 0.77 & 0.75 & & \\
\hline 2 & 0.75 & 0.03 & - & 0.76 & 0.78 & 0.77 & 0.79 & 0.04 & - \\
\hline 3 & 0.77 & & & 0.77 & 0.77 & 0.77 & 0.77 & & \\
\hline
\end{tabular}

ME, metabolizable energy; BW, body weight.

${ }^{*}$ Residual standard error of the model $Y=\mu+P+S+P \times S+\varepsilon$ for trial 1 where $\mu$ is the average intercept, $P$ is the effect of $C P$ content of the diet, $S$ is the effect of stage of fattening and $P \times S$ is the interaction between $C P$ content of the diet and stage or $Y=\mu+F+S+F \times S+\varepsilon$ for trial 2 , where $\mu$ is the average intercept, $F$ is the effect of

feeding level, $S$ is the effect of stage of fattening and $F \times S$ is the interaction between feeding level and stage.

$\dagger \mathrm{F}$, effect of feeding level $(P<0.05)$; $\mathrm{S}$, effect of stage of fattening $(P<0.05)$.

$\mp$ Mean BW and ME intake during the $6 \mathrm{~d}$ prior to fasting.

§Only three values were available.

Table 5. Duration and energy cost of standing activity in veal calves*

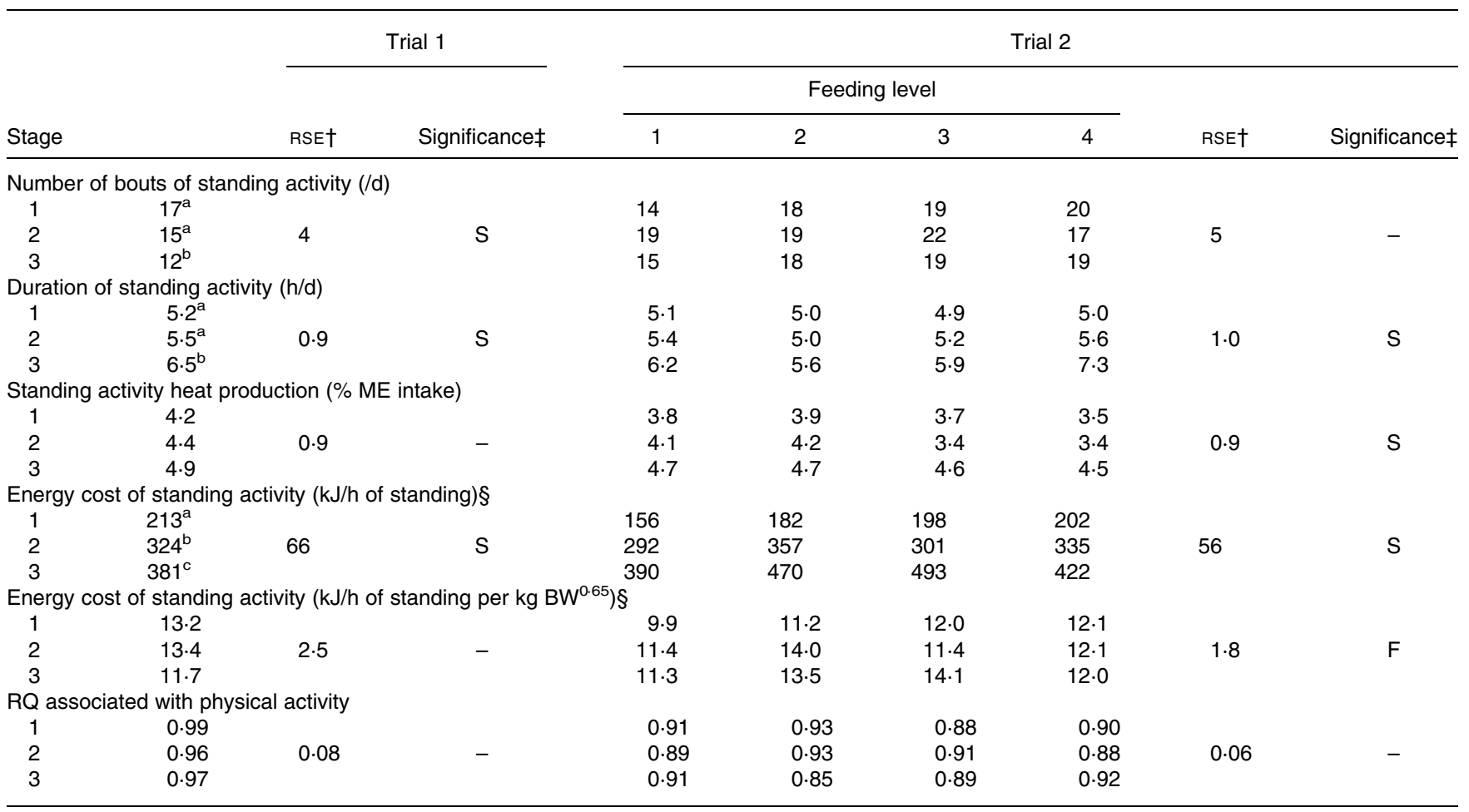

ME, metabolizable energy; BW, body weight.

${ }^{*}$ Measurements were conducted on the $6 \mathrm{~d}$ prior to fasting (see Tables 1 and 4 for mean BW and ME intakes).

†Residual standard error of the model $\mathrm{Y}=\mu+\mathrm{P}+\mathrm{S}+\mathrm{P} \times \mathrm{S}+\varepsilon$ for trial 1 where $\mu$ is the average intercept, $\mathrm{P}$ is the effect of the crude protein (CP) content of the diet, $\mathrm{S}$ is the effect of stage of fattening and $P \times S$ is the interaction between $C P$ content of the diet and stage, and $Y=\mu+F+S+F \times S+\varepsilon$ for trial 2 , where $\mu$ is the average intercept, $\mathrm{F}$ is the effect of feeding level, $\mathrm{S}$ is the effect of stage of fattening and $\mathrm{F} \times \mathrm{S}$ is the interaction between feeding level and stage.

$\ddagger \mathrm{F}$, effect of feeding level $(P<0.05)$; $\mathrm{S}$, effect of stage of fattening $(P<0.05)$.

$\S$ According to model M3, energy cost of $1 \mathrm{~h}$ standing could be calculated as $12.4 \mathrm{~kJ} / \mathrm{kg} \mathrm{BW}^{0.65}$ (asymptotic SE $0.24, P=0.14$; extra-sum-of-squares test). 
in trial 1 (Table 5). In trial 2 , it also increased as animals became older but tended also to increase with increasing feeding level $(P=0 \cdot 07)$. In addition, values for similar ME intake were close at each stage between both trials. The RQ associated with activity heat production was not affected by stage in either trial or by feeding level in trial 2 and averaged 0.94 (Table 5).

When considering the general allometric model M3, hourly heat production due to standing could be considered as proportional to $\mathrm{BW}$ raised to the power 0.65 for data from both trials $(P=0.06$; extra-sum-of-squares test). Indeed, if expressed per $\mathrm{kg} \mathrm{BW}^{065}$, the hourly $\mathrm{C}_{\mathrm{st}}$ activity did not differ among stages for both trials (Table 5); in trial 2, that hourly $\mathrm{C}_{\mathrm{st}}$ was lower $(P<0 \cdot 10)$ at the lowest feeding level. Ignoring that latter effect, $\mathrm{C}_{\mathrm{st}}$ could be calculated for both trials as $12.4 \mathrm{~kJ} / \mathrm{kg} \mathrm{BW}^{0.65}$ per h (ASE $0 \cdot 24, P=0 \cdot 14$; extrasum-of-squares test).

\section{Discussion}

\section{Fasting heat production: methodological aspects}

The use of the logarithmic transformation (model M2) is justified by the difference in error distribution between models M1 and M2. The distribution of residuals is more homogeneous (Fig. 2 (B)) when using model M2 whereas residuals appeared to be proportional to predicted values of $\mathrm{FHP}_{0}$ with model M1 (Fig. 2 (A)). This latter assumption is also validated by the equality of variances test performed between the two groups of residuals. Nevertheless, with regard to model M2, the bias in residuals distribution when considering a 0.75 exponent for body weight (Table 3), especially for the lowest fitted values or the lightest animals, indicates that this coefficient is clearly not adequate for calculating metabolic body size over the whole fattening period and hence fitting $\mathrm{FHP}_{0}$. The test of the extra-sum-of-squares confirms this $(P<0 \cdot 01)$.

A coefficient of $0.80,0.85$ or 0.90 can be accepted for describing the $\mathrm{FHP}_{0}$ relative to $\mathrm{BW}(P=0.23,0.73$ and $0 \cdot 22$, respectively; extra-sum-of-squares test). Nevertheless, the error distribution for the 0.85 exponent was less biased than with 0.80 or 0.90 . Consequently, the coefficient 0.85 appeared to be the most adequate exponent for expressing FHP and might also be the most adequate for calculating metabolic body size in veal calves. Previous studies conducted in growing pigs indicated that the 0.75 exponent was not adequate for expressing metabolic body size and proposed values for both pigs and poultry that are lower than $0 \cdot 75^{(29)}$. The coefficient obtained in the present studies is higher than 0.75 . As in pigs and poultry, our measurements of $\mathrm{FHP}_{0}$ in calves were conducted in a thermoneutral environment ${ }^{(30)}$ and excluded the contribution of activity. The contribution of visceral mass to $\mathrm{FHP}_{0}$ is important (more than $35 \%$ due to liver, heart and kidneys) $)^{(31)}$ and the relative growth of these organs has to be considered as a factor influencing the metabolic exponent. In the case of pigs, the metabolic exponent for growing pigs was 0.60 and the allometric coefficient of growth of visceral organs was about $0 \cdot 70^{(32)}$. The allometric growth coefficients of visceral organs of veal calves (receiving no solid feed and growing at three different rates up to $105 \mathrm{~kg}$ ) are all higher than 1 (from 1.2 to $1 \cdot 5)^{(5)}$ and it is still about $1 \cdot 0$ when considering heavier ruminating cattle of approximately
$300 \mathrm{~kg}^{(33)}$. This suggests that visceral organs of calves grow faster than the overall body, at least for the BW range considered in the present study, whereas in pigs the relative growth of these organs is lower than the overall body; this may explain the higher value of the exponent for the metabolic body size in calves compared to those of other species.

\section{Variations of fasting heat production with feeding level}

The value of $\mathrm{FHP}_{0}$ calculated in this study for a calf fed near ad libitum $\left(310 \mathrm{~kJ} / \mathrm{kg} \mathrm{BW}^{0.85}\right)$ is higher than values previously measured in 45-48 kg Friesian calves (from 264 to $304 \mathrm{~kJ} / \mathrm{kg}$ $\mathrm{BW}^{085}$, including the contribution of physical activity $)^{(34)}$. The latter values were obtained after $2 \mathrm{~d}$ of fasting and the long fasting period may have contributed to the lower values ${ }^{(35)}$. However, other values measured in heavier British Friesian growing steers (BW about $100 \mathrm{~kg}$ ) after $2 \mathrm{~d}$ of starvation were close to those obtained in our studies $\left(300-350 \mathrm{~kJ} / \mathrm{kg} \mathrm{BW}{ }^{085}\right)^{(36)}$. In our trials, $\mathrm{FHP}_{0}$ was determined over a $23 \mathrm{~h}$ fasting period following a morning meal. This fasting period was relatively short compared to previous studies in calves ${ }^{(33)}$. However, a long period of fasting may favour situations in which stress and behavioural disturbances increase. Moreover, the $\mathrm{FHP}_{0}$ measurements in our study may be more representative for producing animals than those measured during prolonged fasting, as it includes part of the 'remnant' heat production due to digestive and absorptive processes. In fact, the variations observed between literature values and those presented in this paper may be due to methodological differences but also to the differences in ME intake prior to fasting.

The effect of ME intake (prior to fasting) on $\mathrm{FHP}_{0}$ has been observed before in calves ${ }^{(37)}$ where a reduction in ME intake of $12-13 \%$ caused a decrease in $\mathrm{FHP}_{0}$ of $14-16 \%$. Our results were obtained at lower ME intakes but in the second trial an important reduction in $\mathrm{ME}$ intake was imposed (from 20 to $23 \%$ depending on stage of fattening), which caused a reduction of $10-13 \%$ in $\mathrm{FHP}_{0}$. The weight of visceral organs is largely influenced by level of ingestion ${ }^{(38)}$ and as the contribution of visceral organs to $\mathrm{FHP}_{0}$ is important, it is rather logical to relate $\mathrm{FHP}_{0}$ to previous $\mathrm{ME}$ intake. Finally, the contribution of $\mathrm{ME}$ intake to $\mathrm{FHP}_{0}$ measured in these trials is close to the one measured in young Friesian

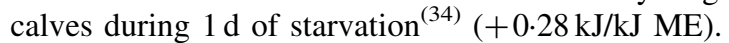

\section{Energy cost of physical activity during standing}

In trial 1, the total daily duration of standing was slightly lower than values measured in veal calves housed in similar housing conditions (metabolism cage in respiration chamber; $5 \mathrm{~h} 40 \mathrm{~min})^{(21)}$. Total standing duration increased from $5 \mathrm{~h}$ to more than $6 \mathrm{~h}$ when animals got older which is consistent with behavioural observations ${ }^{(18)}$. The standing duration has to be related to housing conditions since, for instance, individually-housed calves stand up for less time than group-housed calves $^{(18)}$. Our measurement conditions are particular since calves were housed individually without visual contact with other calves. The audio system may favour partial synchronization between the two animals since the standing up of one calf and associated noise may favour the standing up of the other calf: the overall standing duration cannot then be 
directly compared to behavioural observations in production units. Nevertheless, expressing the energy cost of activity per hour of standing position allows extrapolation of our results from individual animals to group-housed animals and therefore to farm conditions.

Contrary to results from Roefs et al. ${ }^{(39)}$, total daily duration of standing in trial 2 was not affected by feeding level whatever the stage. The number of standing bouts also remained constant with increasing feeding level which is surprising because it is generally thought that feed restriction results in higher levels of activity. Nevertheless, the lowest feeding level used in our trials could not be considered as a severe feed restriction since quantity of ME ingested corresponded to about $70 \%$ of the ad libitum intake. Finally, daily standing activity heat production remained constant in trial 2 while calves received increasing quantities of feed, in accordance with previous study ${ }^{(8,39)}$. Nevertheless, the fraction of ME intake used for standing activity also remained constant over variable feeding levels but increased as animals get older in both trials. Moreover, this fraction of ME intake is three times lower in calves (approximately $4.3 \%$ ) than values estimated in pigs ${ }^{(40)}$.

The daily $\mathrm{C}_{\mathrm{st}}$ measured in this study was higher than the results ${ }^{(7,21)}$ calculated in young calves as the difference between average heat productions during standing and lying $(31 \mathrm{~kJ} / \mathrm{kg}$ $\mathrm{BW}^{0.65}$ per $\left.\mathrm{d}\right)$. However, the calves stood up for less time than those in our trials $(4.6 v .5 \cdot 0 \mathrm{~h} / \mathrm{d})$. When relating these results to the duration of standing, the results of Schrama et al. ${ }^{\text {(7) }}$ obtained at an ambient temperature of $18^{\circ} \mathrm{C}$ are in close agreement with those obtained in trial 2 during the first fattening stage with calves receiving the lowest feeding levels. Other values, obtained with heavier calves $(150 \mathrm{~kg} \mathrm{BW})$ were higher (from 114 to $135 \mathrm{~kJ}^{\prime} / \mathrm{kg} \mathrm{BW}^{0.65}$ per d) than those calculated in the present study but they included contribution of movements of the animal during both standing and lying positions ${ }^{(8)}$. Our calculation procedure accounted for the extra $\mathrm{C}_{\mathrm{st}}$ above a 'baseline' activity energy cost measured during periods of lying. Our measurements indicated that this latter part accounted for approximately $45 \%$ of the total heat production due to physical activity (for both lying and standing). When the energy costs of physical activity during both standing and lying positions are added, our results are in close agreement with those of van den Borne et al. ${ }^{(8)}$. For heavier cattle (mean BW $273 \mathrm{~kg}$ ), the extra heat production due to standing position could be estimated at $13.5 \mathrm{~kJ} / \mathrm{kg}$ fasted BW per $\mathrm{d}^{(41)}$ which is equivalent to $96 \mathrm{~kJ} / \mathrm{kg}$ $\mathrm{BW}^{0.65}$ per d for a $273 \mathrm{~kg}$ animal. Finally, this latter result was higher than values measured during the third stage of fattening.

According to our results, hourly $\mathrm{C}_{\mathrm{st}}$ was proportional to $\mathrm{BW}^{0.65}$. In fact, the simple allometric relation proposed was not fully adequate since hourly values (expressed per $\mathrm{kg}$ BW ${ }^{0.65}$ ) were affected by feeding level in trial 2 . Nevertheless, this effect is not easily explainable since it is not similar across stages. Moreover, activity RQ (which were higher than those for fasting, in accordance with previous results in pigs $^{(20)}$ ) did not indicate any difference in nutrient supply for physical activity.

\section{Conclusions}

Energy requirements in veal calves are expressed as the sum of requirement for maintenance and growth requirement. Moreover, the dynamics of energy partitioning between physical activity, feed intake and BMR contributes to a new understanding of energy requirements of veal calves. So far, maintenance requirements have been expressed as a function of $\mathrm{BW}^{075}$. The value of the exponent of $\mathrm{BW}$ is of less importance for short growing periods but as slaughter weight increases, it is important to use a value valid for the whole fattening period. Our results indicate that the 0.85 exponent would be appropriate over the 60 to $260 \mathrm{~kg} \mathrm{BW}$ growing period. Further recommendations should also take into account the contribution of physical activity in energy expenditure. The estimated energy cost of standing activity $(12.4 \mathrm{~kJ} /$ $\mathrm{kg} \mathrm{BW}^{0.65}$ per h) may be extrapolated to breeding systems, when completed with behavioural observations of duration of standing.

\section{Acknowledgements}

These experiments were a part of a research project conducted jointly by INRA and Institut de l'Elevage with the financial support of Bretagne and Pays de la Loire Regions and Interveaux and SDVF French veal calves organizations. The authors would like to thank A. Chauvin, O. Glais, B. Janson, R. Leborgne, F. Le Gouevec, V. Piedvache and J.-F. Rouaud for animal care, R. Delaunay, B. Fontaine and D. Guillard for animal transportation and Y. Jaguelin and A. Pasquier for laboratory analyses. The sponsors of the project and the authors had no conflict of interests.

\section{References}

1. NRC (2001) Nutrient requirements of the young calf. In Nutrient Requirements of Dairy Cattle, pp. 214-233. Washington, DC: National Academy Press.

2. Toullec R (1988) Alimentation du veau de boucherie. In Alimentation des Bovins, Ovins et Caprins, pp. 185-199 [R Jarrige, editor]. Paris: INRA.

3. Bartlett KS, McKeith FK, Vandehaar MJ, Dahl GE \& Drackley JK (2006) Growth and body composition of dairy calves fed milk replacers containing different amounts of protein at two feeding rates. J Anim Sci 84, 1454-1467.

4. Blome RM, Drackley JK, McKeith FK, Hutjens MF \& McCoy GC (2003) Growth, nutrient utilization, and body composition of dairy calves fed milk replacers containing different amounts of protein. J Anim Sci 81, 1641-1655.

5. Diaz MC, Van Amburgh ME, Smith JM, Kelsey JM \& Hutten EL (2001) Composition of growth of Holstein calves fed milk replacer from birth to 105 -kilogram body weight. J Dairy Sci 84, 830-842.

6. Gerrits WJ, Tolman GH, Schrama JW, Tamminga S, Bosch MW \& Verstegen MW (1996) Effect of protein and protein-free energy intake on protein and fat deposition rates in preruminant calves of 80 to $240 \mathrm{~kg}$ live weight. J Anim Sci 74, 2129-2139.

7. Schrama JW, Arieli A, Brandsma HA, Luiting P \& Verstegen MW (1993) Thermal requirements of young calves during standing and lying. J Anim Sci 71, 3285-3292.

8. van den Borne JJGC, Verstegen MWA, Alferink SJJ, Giebels RMM \& Gerrits WJJ (2006) Effects of feeding frequency and feeding level on nutrient utilization in heavy preruminant calves. J Dairy Sci 89, 3578-3586.

9. Noblet J, Shi XS \& Dubois S (1993) Metabolic utilization of dietary energy and nutrients for maintenance energy 
requirements in sows: basis for a net energy system. $\mathrm{Br} J$ Nutr 70, 407-419.

10. Noblet J, Karege C, Dubois S \& van Milgen J (1999) Metabolic utilization of energy and maintenance requirements in growing pigs: effects of sex and genotype. J Anim Sci 77, 1208-1216.

11. Baker JF, Buckley BA, Dickerson GE \& Nienaber JA (1991) Body composition and fasting heat production from birth to 14 months of age for three biological types of beef heifers. J Anim Sci 69, 4406-4418.

12. McNab BK (1997) On the utility of uniformity in the definition of basal rate of metabolism. Physiol Zool 70, 718-720.

13. Kleiber M (1965) Metabolic body size. In Energy Metabolism. Proceedings of the 3rd Symposium of the European Association of Animal Production, pp. 427-435 [KL Blaxter, editor]. Troon Scotland, May 1964, publication no. 11. London: Academic Press.

14. da Silva JKL, Garcia GJM \& Barbosa LA (2006) Allometric scaling laws of metabolism. Phys Life Rev 3, 229-261.

15. Thonney ML, Touchberry RW, Goodrich RD \& Meiske JC (1976) Instraspecies relationship between fasting heat production and body weight: a reevaluation of $\mathrm{W}^{075}$. J Anim Sci 43, 692-704.

16. Feldman HA \& McMahon TA (1983) The mass exponent for energy metabolism is not a statistical artifact. Respir Physiol 52, 149-163.

17. Brown D \& Mount LE (1982) The metabolic body size of the growing pig. Livest Prod Sci 9, 389-398.

18. Bokkers EAM \& Koene P (2001) Activity, oral behaviour and slaughter data as welfare indicators in veal calves: a comparison of three housing systems. Appl Anim Behav Sci 75, 1-15.

19. Schrama JW (1993) Energy metabolism of young, unadapted calves. PhD Thesis, Wageningen Agricultural University.

20. van Milgen J, Bernier JF, Lecozler Y, Dubois S \& Noblet J (1998) Major determinants of fasting heat production and energetic cost of activity in growing pigs of different body weight and breed/castration combination. Br J Nutr 79, 509-517.

21. Ortigues I, Martin C, Vermorel M \& Anglaret Y (1994) Energycost of standing and circadian changes in energy-expenditure in the preruminant calf. J Anim Sci 72, 2131-2140.

22. Vermorel M, Bouvier JC, Bonnet Y \& Fauconneau G (1973) Construction et fonctionnement de deux chambres respiratoires du type "circuit ouvert" pour jeunes bovins. Ann Biol Anim Bioch Biophys 13, 659-681.

23. Quiniou N, Noblet J, van Milgen J \& Dubois S (2001) Modelling heat production and energy balance in group-housed growing pigs exposed to low or high ambient temperatures. $\mathrm{Br}$ J Nutr 85, 97-106.

24. van Milgen J, Noblet J, Dubois S \& Bernier JF (1997) Dynamic aspects of oxygen consumption and carbon dioxide production in swine. Br J Nutr 78, 397-410.

25. AOAC (1990) Official Methods of Analysis, 15th ed. [Association of Official Analytical Chemists, editor]. Arlington, VA, USA: AOAC.

26. Brouwer E (1965) Report of sub-comittee on constants and factors. In Energy Metabolism. Proceedings of the 3rd Symposium of the European Association of Animal Production, pp. 441-443 [KL Blaxter, editor]. Troon Scotland, May 1964, publication no. 11. London: Academic Press.

27. SAS (2004) SAS/STAT ${ }^{\circledR} 9.1$ User's Guide. Cary, NC: Statistical Analytical Systems.

28. Ratkowsky DA (1983) Nonlinear Regression Modelling, pp. 276. New York: Marcel Dekker, Inc.

29. Noblet J, Karege C \& Dubois S (1989) Influence of sex and genotype on energy utilisation in growing pigs. In Energy Metabolism of Farm Animals. Proceedings of the 11th Symposium of the European Association of Animal Production, pp. 57-60 [Y van der Honing and WH Close, editors]. Linteren the Netherlands, September 1988, publication no. 43. Wageningen: Centre for Agricultural Publishing and Documentation.

30. Vermorel M, Quillet JP \& Toullec R (1978) Les problèmes d'environnement et d'habitat des veaux. Bull Tech Inf 328329, 225-235.

31. Ferrell CL, Garrett WN, Hinman N \& Grichting G (1976) Energy utilization by pregnant and non-pregnant heifers. J Anim Sci 42, 937-950.

32. Noblet J, Karege C \& Dubois S (1991) Influence of growth potential on energy requirements for maintenance in growing pigs. In Energy Metabolism of Farm Animals. Proceedings of the 12th Symposium of the European Association of Animal Production, pp. 107-110 [C Wenk and H Boessinger, editors]. Kartause Ittingen Switzerland, September 1991, publication no. 48. Zürich: ETH.

33. Robelin J (1986) Composition corporelle des bovins: évolution au cours du développement et différences entre races. PhD Thesis, Université de Clermont-Ferrand II, Clermont-Ferrand, France.

34. Holmes CW \& Davey AWF (1976) The energy metabolism of young jersey and friesian calves fed fresh milk. Anim Prod 23, 43.

35. Close WH \& Mount LE (1975) The rate of heat loss during fasting in the growing pig. Br J Nutr 34, 279-290.

36. Webster AJF, Brockway JM \& Smith JS (1974) Prediction of the energy requirements for growth in beef cattle. 1 . The irrelevance of fasting metabolism. Anim Prod 19, 127-139.

37. Vermorel M, Bouvier JC \& Geay Y (1980) Utilisation de l'énergie des aliments par le veau ruminant. Influence de l'apport de lait, du niveau d'alimentation et de l'âge du veau. Ann Zootech 29, 65-86.

38. Koong LJ, Nienaber JA, Pekas JC \& Yen JT (1982) Effects of plane of nutrition on organ size and fasting heat production in pigs. J Nutr 112, 1638-1642.

39. Roefs JPA, Schrama JW \& Schouten WGP (1996) Effect of temperature and food intake on metabolic rate and posture of preruminant calves. Physiol Behav 60, 203-209.

40. Noblet J, Shi XS \& Dubois S (1993) Energy cost of standing activity in sows. Livest Prod Sci 34, 127-136.

41. Vercoe JE (1973) The energy cost of standing and lying in adult cattle. Br J Nutr 30, 207-210. 